\section{Establishment and biological characteristics of a Jingning chicken embryonic fibroblast bank}

\author{
C. Bai, ${ }^{1}$ D. Wang, ${ }^{2}$ C. Li, ${ }^{3}$ D. Jin, ${ }^{1}$ C. Li, \\ W. Guan, ${ }^{1}$ Y. $\mathrm{Ma}^{1}$ \\ 'Institute of Animal Sciences, Chinese \\ Academy of Agricultural Sciences, \\ Beijing, China; 'Department of Pathology, \\ Chinese PLA General Hospital, Beijing, \\ China; ${ }^{3}$ Northeast Forestry University, \\ Harbin, China
}

\section{Abstract}

Using tissue explantation and cryopreservation biotechniques, a Jingning chicken embryonic fibroblast bank was successfully established, which includes 43 embryo samples and a stock of 178 cryovials, each one containing $3.0 \times 10^{6}$ cells. Most of the cells were apparently fibroblasts in their morphology, and the population doubling time (PDT) was about $48 \mathrm{~h}$. The total chromosome number of a diploid cell was 78. According to karyotyping and G-banding, the diploid rate in the cell bank was $97.62 \pm 2.12 \%$. The cells were tested for microbial contamination and found free of infections from bacteria, fungi, viruses and mycoplasms. There was no cross-contamination from other cell lines as revealed by lactate dehydrogenase (LDH) and malate dehydrogenase (MDH) isoenzyme polymorphisms. Six fluorescent proteins were transfected into the Jingning chicken embryonic fibroblasts, and the transfection efficiencies of these genes were between 10.1 and $41.9 \%$. All the tests showed that the quality of the cell line conforms to the quality criteria of the ATCC (American type culture collection). This work succeeded not only in preserving the genetic resources of Jingning chicken, but it also established a new protocol to preserve endangered animal breeds.

\section{Introduction}

Genetic diversity of China livestock and poultry had been seriously reduced, and some high-quality species of livestock and poultry are on the brink of extinction, especially due to the exacerbation of environmental pollution and the development of animal husbandry. If these genetic resources are not preserved in any forms before their extinction, they will be irreparably lost; it is therefore crucial to under- take realistic measures to conserve endangered species. ${ }^{1}$ Currently, semen, embryos, genomic and cDNA libraries are all conventional methods to preserve single animals. In addition, since the entire genome of a species is contained in the nucleus of somatic cells, modern cloning techniques have made fibroblasts an attractive resource for safeguarding animal genetic materials. ${ }^{2}$ In addition, the establishment of an animal somatic cell bank can not only preserve this genetic resource at the cell level, but also provide a precious experimental material for investigation in cell biology, genomics and post-genomics, and for embryonic engineering. Jingning chicken, also known as Sanhuang chicken or White-ear chicken, originates in the provinces of Yushan, Shangrao and Guangfeng, China and is characterized by small body, high fecundity and tender flesh. As one of the chicken local breeds in China, Jingning chicken has enjoyed a high reputation in Jiangxi Province ever since the Song dynasty, and was well sold in international market during the Qing dynasty. ${ }^{3}$ Jingning chicken has been included in the 138 national protected species list by the Chinese Government in 2006.

In the present research, we succeeded in constructing a fibroblast bank through primary explantation and programmed cryopreservation, and tested the quality of the cell lines obtained. The genetic resource of this valuable local breed has thus been preserved through somatic cells for long-term storage. In addition, this technical platform will provide a technical and theoretical support to conserve other animal genetic resources at the cell level.

\section{Materials and Methods}

The 8-day old embryos of Jingning chicken used in this research were provided by the chicken breeding farm of the Chinese Academy of Agricultural Sciences, Beijing, China. Except otherwise specifically mentioned, all reagents were obtained from Sigma Chemical Co. (St. Louis, MO, USA).

\section{Isolation and culture of Jingning chicken embryonic fibroblasts}

Jingning chicken eggs incubated for 8 days were sterilized using alcohol swabs, and then the embryos were isolated and washed three times with phosphate buffered saline (PBS). Embryos were chopped into pieces of $1 \mathrm{~mm}^{3}$ and placed onto the surface of a tissue culture flask, at $37^{\circ} \mathrm{C}$ in a humidified air atmosphere containing $5 \%$ of $\mathrm{CO}_{2}$, for 3-4 h. Modified Eagle's medium (MEM) (Gibco, Carlsbad, CA, USA) containing $10 \%$ fetal bovine serum
Correspondence: Weijun Guan and Yuehui Ma Institute of Animal Sciences, Chinese Academy of Agricultural Sciences, Beijing 100193, China. Tel. +86.10.62815992 - Fax: +86.10.62813463. E-mail:wjguan86@iascaas.net.cn and yuehui.ma@263.net

Key words: Jingning chicken, fibroblasts, genetic conservation, biological characteristics

Contributions: $\mathrm{CB}$ and DW contributed equally to the work.

Acknowledgements: this research was supported by the "863" National Major Research Program (2006AA10Z198, 2007AA10Z170), National Key Technology R\&D Program (2006BAD13B08, 2008BADB2B01), National Scientific Foundation of China (30671539) and Project (no. 2008ZX08009-003) from the Ministry of Agriculture of China for transgenic research.

Received for publication: 30 September 2010 . Accepted for publication: 9 December 2010.

This work is licensed under a Creative Commons Attribution 3.0 License (by-nc 3.0).

(C)Copyright C. Bai et al., 2011

Licensee PAGEPress, Italy

European Journal of Histochemistry 2011; 55:e4 doi:10.4081/ejh.2011.e4

(HyClone, Logan, UT, USA) was added into the inverted flask and cultured overnight. The medium was refreshed after 2-3 d. The cells were harvested at $80-90 \%$ confluence using $0.25 \%$ trypsin $(\mathrm{m} / \mathrm{v})$ solution and were separated into culture flasks at the ratio of $1: 2$ or $1: 3 .{ }^{4,5}$

After three passages, the cultured cells were suspended in media containing 40\% MEM, $50 \%$ fetal bovine serum and $10 \%$ dimethyl sulfoxide (DMSO). Cells in logarithmic growth phase were counted with a hemocytometer and adjusted to a density of $3-4 \times 10^{6}$ viable cells per $\mathrm{mL}$. Aliquots of the cell suspension were transferred into sterile cryovials labeled with the breed name, gender, freezing serial number and date. The vials were sealed and kept at $4{ }^{\circ} \mathrm{C}$ for 20-30 min to equilibrate DMSO, put into a programmed preservation system, and finally transferred to liquid nitrogen for long-term storage. ${ }^{6}$ Vials taken from the liquid nitrogen were thawed in a $42^{\circ} \mathrm{C}$ water bath, then transferred to flasks with MEM containing 10\% fetal bovine serum and cultured at $37^{\circ} \mathrm{C}$ with $5 \%$ $\mathrm{CO}_{2}$. The medium was renewed after $24 \mathrm{~h}$.

\section{Estimation of cell viability by trypan blue exclusion test}

Viabilities before freezing and after thawing were determined using the Trypan blue exclusion test. The number of non-viable cells was determined by counting 1000 cells. $^{\text {? }}$ 


\section{Growth dynamics}

Cells were plated onto 24-well microplates (Corning, Santa Clara, CA, USA) at the density of approximately $1.5 \times 10^{5}$ cells per well, cultured for $7 \mathrm{~d}$ and counted every day ( 3 wells each time) afterwards. The mean cell counts at each time point were then used to plot a growth curve, based on which the population doubling time (PDT) was calculated. ${ }^{7-9}$

\section{Microbial analysis}

\section{Detection of bacteria and fungi}

The cells were cultured in complete MEM (Gibco, Carlsbad, CA, USA) media free of antibiotics and observed for the presence of bacteria and fungi at $3 \mathrm{~d}$ after subculture, according to the method described by Doyle et al. ${ }^{10}$

\section{Detection of mycoplasms}

According to the protocol of the American type culture collection (ATCC), the cells were cultured in antibiotic-free medium for at least 1 week, and then fixed and stained with Hoechst 33258 (Invitrogen, Carlsbad, CA, USA). ${ }^{11}$

\section{Virus detection}

Hay's hemadsorption protocol was used to examine the samples for cytopathogenesis using phase-contrast microscopy (Olympus Corp., Tokyo, Japan). ${ }^{12,13}$

\section{Karyotyping and chromosome analysis}

Chromosome spreads were prepared, fixed and stained following standard methods. ${ }^{14}$ The cells were incubated, when $70-80 \%$ confluent, with $0.1 \mu \mathrm{g} / \mathrm{mL}$ of colchine for $4 \mathrm{~h}$. Hypotonic treatment is a major influential factors in karyotyping, which aims at swelling the cells and spreading the chromosomes; to obtain good metaphase spreadings, the time of the hypotonic treatment was tightly controlled within 40 min. Cells were harvested when 80 $90 \%$ confluent, subjected to hypotonic treatment and fixed, and the chromosome numbers were counted from 100 spreads after Giemsa staining, using an $100 \times$ oil immersion objective. Relative length, arm ratio and centromeric index, and kinetochore type were calculated according to the protocol described by Kawarai et al. ${ }^{15}$

\section{Isoenzyme polymorphisms}

Isoenzyme patterns of lactic dehydrogenase (LDH) and malic dehydrogenase (MDH) were detected using vertical slab non-continuous polyacrylamide gel electrophoresis (PAGE) assay. According to the method described by Simpson, ${ }^{11}$ the cells were harvested, and protein extraction solution $(0.9 \%$ Triton X-100,
$0.06 \mathrm{mM} \mathrm{NaCl}$ :EDTA in mass ratio 1:15) was added after the cell concentration was adjusted to $5 \times 10^{7}$ cells $/ \mathrm{mL}$. Then the mixture was centrifuged and the supernatant was aliquoted and stored at $-80^{\circ} \mathrm{C}$. Liquid sucrose [ $40 \%$ $(\mathrm{m} / \mathrm{v})]$ and the samples were mixed [1:1 (v/v)] and then loaded into the individual lanes of the polyacrylamide gel. ${ }^{11}$

\section{Expression of fluorescent proteins in Jingning chicken fibroblasts}

According to the methods described by Wu $e t$ $a l .{ }^{13}$ three fluorescent proteins (pDsRed1-N1, pEGFP-N3 and pEYFP-N1) were transfected into fibroblasts using plasmid DNA (BD Biosciences Clontech, Japan) and Lipofectamine 2000 (Invitrogen, Carlsbad, CA, USA). The cultured cells were observed at $24 \mathrm{~h}, 48 \mathrm{~h}$, 72 h, 96 h, 1 week, 2 weeks and 1 month after transfection. Expression of the three fluorescent protein genes was observed under a confocal microscope (Nikon TE-2000-E, Japan) with excitation wavelengths of $543 \mathrm{~nm}, 488 \mathrm{~nm}$ and $488 \mathrm{~nm}$ and $543 \mathrm{~nm}$, respectively. For each group, 10 microscopic fields were considered to calculate the transfection efficiencies as the ratio of positive cells to the total cells in the field.13 Forty-eight $\mathrm{h}$ after transfection, the apoptotic rates were estimated on cell cultures after staining nuclear DNA with DAPI. The effect of exogenous gene transfection on cell viability was also assessed by the Trypan blue exclusion test.
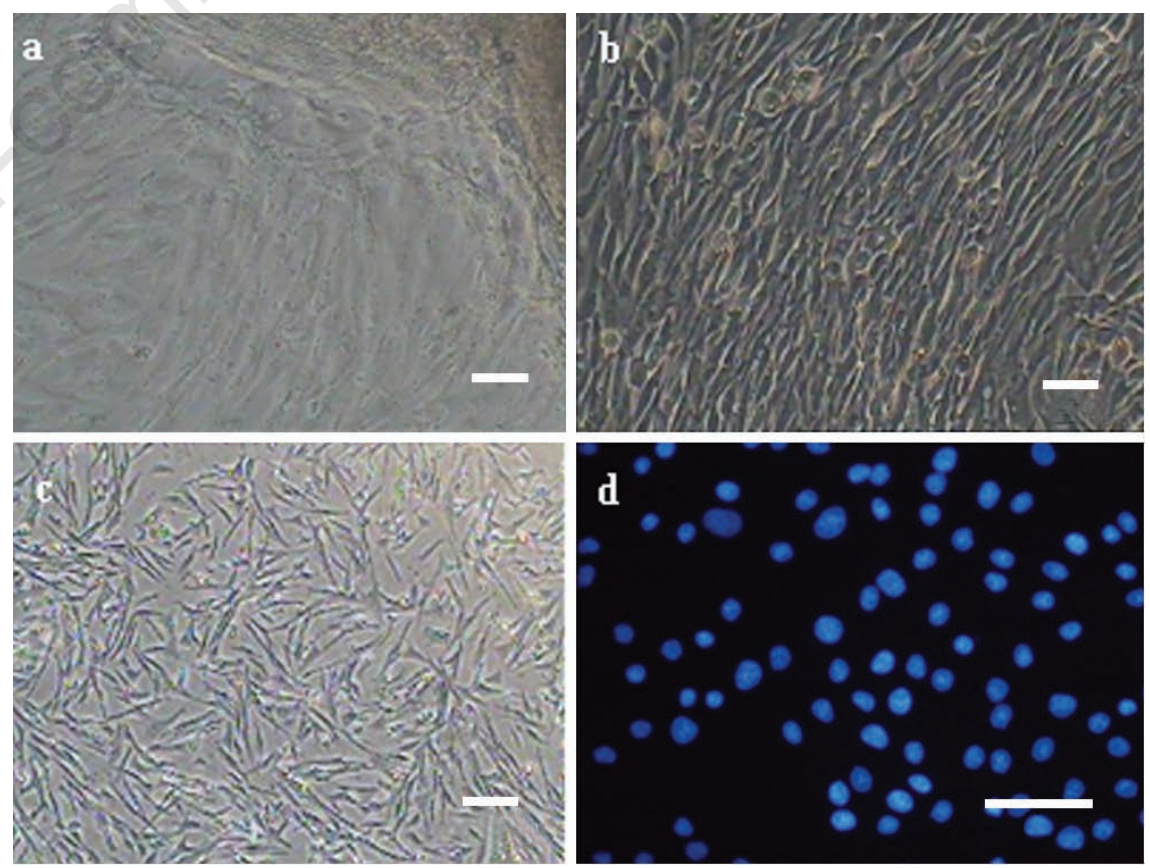

Figure 1. Morphology of Jingning chicken embryonic fibroblasts cultured in vitro. (a) 1$2 \mathrm{~d}$ after explanting; (b) before cryopreservation; (c) $24 \mathrm{~h}$ after recovery; (d) Jingning chicken fibroblasts stained with Hoechst 33258. 
period and no abnormalities could be observed under the microscope. The results indicated that the Jingning chicken fibroblasts were free of bacterial contamination and the fibroblast cultures were apparently free of mycoplasms. Would there be abundant punctiform and filiform blue fluorescence in the nucleoli, it could be concluded that the cells were contaminated by mycoplasmas (Figure 1d), as shown by the

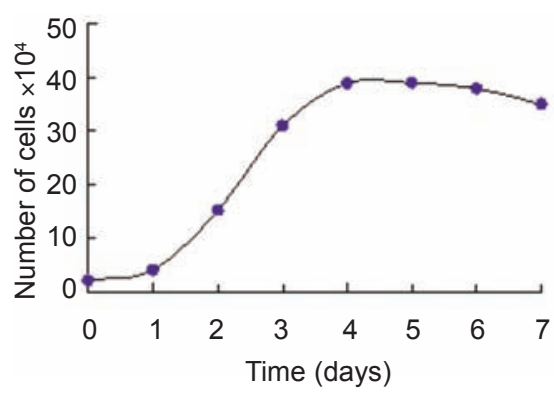

Figure 2. Growth curve of Jingning chicken embryonic fibroblasts.

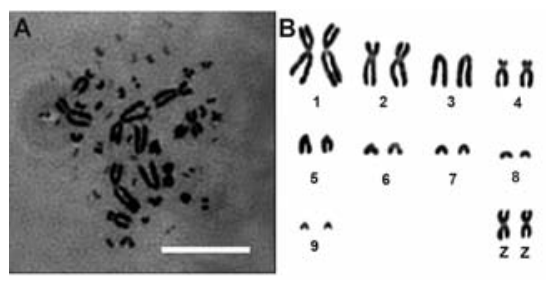

Figure 3. (A) representative spread of Jingning chicken in metaphase ( $\left.\sigma^{\prime}\right)$; (B) karyotype of Jingning chicken fibroblasts $\left(\sigma^{\prime}\right)$.

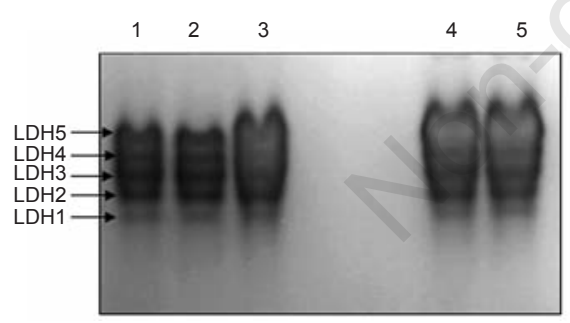

Figure 4. Isoenzyme patterns of lactate dehydrogenases from Jingning and Langshan chickens. Lanes 1 and 2, Jingning chicken; lanes 3,4 and 5, Langshan chicken.

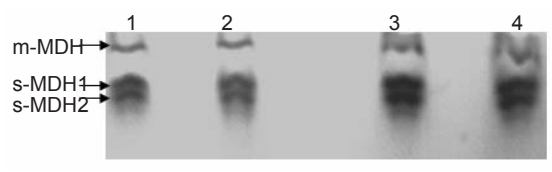

Figure 5. Isoenzyme patterns of malate dehydrogenases from Jingning and Langshan chickens. Lanes 1 and 2, Jingning chicken; lanes 3 and 4, Langshan chicken. positive result of Li et al. ${ }^{16}$ The tests for virus contamination were both negative as well, as indicated by the cytopathogenic evidence and the hemadsorption test.

\section{Karyogram and chromosome num- ber of Jingning chicken}

The chromosome number of diploid Jingning chicken is 78, including 10 pairs of macrochromosomes and 29 pairs of microchromosomes. The sex chromosome type is $\mathrm{ZZ}\left(\sigma^{\circ}\right) / \mathrm{ZW}\left({ }^{\circ}\right)$ (Figure 3). The parameters including relative length, centromere index and kinetochore type are shown in Table 1. In this experiment, 100 representative spreads of metaphases at passages 3-5 were observed under the microscope to count the chromosome numbers, and the mean proportion of diploid cells was $97.62 \pm 2.12 \%$ (mean value $\pm \mathrm{SD}$ ).

\section{Isoenzyme polymorphisms}

The profiles of isoenzyme polymorphisms might be characteristic in a given species or tissue. ${ }^{17}$ Polymorphism analysis of isoenzymes is currently a standard method for the quality control to characterize cell lines and prevent interspecies contamination. Isoenzyme patterns of $\mathrm{LDH}$ and $\mathrm{MDH}$ were obtained using vertical slab non-continuous PAGE, stained by Coomassie brilliant blue and compared with those from other breeds (Figures 4 and 5). The LDH RFs were in the order of LDH-5, LDH-4, LDH-3, LDH-2, LDH-1 (Figure 4); while the two bands of $\mathrm{MDH}$ were $\mathrm{m}-\mathrm{MDH}$ and s-MDH (Figure 5). The two chicken breeds have their own characteristic bands, each one with a different migration rate (Table 2 and 3 ). The results indicated that there was no cross-contamination from other cell lines.

Table 1. Chromosome parameters of Jingning chicken (

\begin{tabular}{lrcc} 
Choromosome no. & Relative length (\%) & Centromere index (\%) & Kinetochore type \\
1 & $22.96 \pm 0.027$ & 36.93 & $\mathrm{SM}$ \\
2 & $17.31 \pm 0.022$ & 37.47 & $\mathrm{SM}$ \\
\hline 3 & $11.85 \pm 0.023$ & 0 & $\mathrm{M}$ \\
4 & $10.56 \pm 0.019$ & 27.73 & $\mathrm{SM}$ \\
\hline 5 & $6.24 \pm 0.026$ & 0 & $\mathrm{~T}$ \\
6 & $4.91 \pm 0.035$ & 0 & $\mathrm{~T}$ \\
\hline 7 & $4.05 \pm 0.032$ & 0 & $\mathrm{~T}$ \\
8 & $3.22 \pm 0.024$ & 0 & $\mathrm{~T}$ \\
\hline 9 & $2.71 \pm 0.019$ & 0 & $\mathrm{~T}$ \\
$\mathrm{Z}$ & $11.12 \pm 0.033$ & 44.48 & $\mathrm{M}$ \\
$\mathrm{Z}$ & $11.47 \pm 0.036$ & 44.09 & $\mathrm{M}$ \\
\hline
\end{tabular}

SM, submetacentric chromosomes; T, telocentric chromosomes; M, metacentric chromosomes.

Table 2. Relative migration fonts of lactate dehydrogenase.

\begin{tabular}{lccccc} 
Breeds & LDH1 (\%) & LDH2 (\%) & LDH3 (\%) & LDH4 (\%) & LDH5 (\%) \\
Jingning chicken & 38.89 & 33.33 & 28.89 & 24.44 & 17.78 \\
Langshan chicken & 37.78 & 32.22 & 26.67 & 22.22 & 15.56 \\
\hline
\end{tabular}

Table 3. Relative migration fonts of malate dehydrogenase.

\begin{tabular}{lccc} 
Breeds & m-MIDH (\%) & s-MIDH1 (\%) & s-MIDH2 (\%) \\
Jingning chicken & 8.1 & 14.52 & 20.97 \\
Langshan chicken & 9.68 & 16.13 & 22.58 \\
\hline
\end{tabular}

Table 4. Transfection efficiencies of six fluorescent proteins in Jingning chicken.

\begin{tabular}{lcccccc} 
Time/h & \multicolumn{7}{c}{$\begin{array}{c}\text { Six fluorescent genes } \\
\text { pEYFP-N1 }\end{array}$} & $\begin{array}{c}\text { pDsed1-N1 } \\
(\%)\end{array}$ & $\begin{array}{c}\text { pECFP-N1 } \\
(\%)\end{array}$ & $\begin{array}{c}\text { pECFP-mito } \\
(\%)\end{array}$ \\
\hline 24 & 31.8 & 37.7 & 41.9 & 28.3 & 36.5 & 26.4 \\
48 & 28.5 & 30.6 & 32.2 & 19.4 & 20.3 & 17.8 \\
\hline 72 & 20.2 & 24.8 & 27.7 & 11.2 & 13.5 & 10.1 \\
\hline
\end{tabular}




\section{Expression of exogenous genes in Jingning chicken fibroblasts}

The six fluorescent genes, pEGFP-C1, pEGFPN3, pECFP-N1, pECFP-mito, pEYFP-N1 and pDsRed1-N1 were all highly expressed according to the optimized condition at $24 \mathrm{~h}$, the transfected cells increased gradually as time passed by (Figure 6 and 7); the transfection efficiencies are listed in Table 4. Using confocal microscopy, we observed that a few positive cells began to shrink and disaggregate, and became detached and even dead. The viabilities upon transfection with pEGFP-C1, pEGFP-N3, pECFP-N1, pECFPmito, pEYFP-N1, pDsRed1-N1 were 89.5\%, 88.2\%, $87.6 \%, 86.5 \%, 89.3 \%$ and $87.6 \%$, respectively. Using the Trypan blue exclusion test, it was found that there were no significant differences ( $>>0.05)$ compared with non-transfected controls (91.4\%). Using DAPI, most of the cells had nuclei with evenly distributed blue fluorescence, a few only exhibiting deeply stained fragmented nuclei and apoptotic bodies (Figure 8). The apoptotic rates of cells transfected with pEGFP-N3 and pDsRed1-N1 (other apoptotic rates of cells not shown) were $1.6 \%$ and $1.5 \%$, not significantly different $(\mathrm{P}>0.05)$ from the control ones $(1.4 \%)$.

\section{Discussion}

Chicken embryonic fibroblasts were selected in this experiment as they offer many advantages, such as high vitality and purity, easy access, low probability of bacterial contamination. A Jingning chicken fibroblast line was successfully established from 57 embryo samples by adherent culture. The biological and genetic characteristics may be altered by in vitro culture after many passages, so a minimal number of passages are recommended to protect the cell lines against degeneration. Morphological observation indicated that there were both epithelial cells and fibroblasts during the primary and the first several passages of the explanted tissues. Due to their different tolerance to trypsinization, the fibroblasts detached from the flasks earlier when digested with trypsin and adhered again quickly after passage, whilst most epithelial cells were difficult to adhere, or only did so in an unstable manner and fell off when vibrated. ${ }^{18}$ For this reason, a purified fibroblast line could be obtained after 2-3 passages. Isoenzyme polymorphisms and karyotyping can together effectively confirm the origin of a cell line and identify possible cross-contamination. The genetic stability of cell line is critical to preserve the genetic resources, namely the fibroblasts must maintain the same diploidy as cells in vivo. International standards of poultry karyotype are 8 pairs of large chromosomes, with 6 chromosomes $\mathrm{Z}$ and $\mathrm{W}$, and 30 pairs of microchromosomes. ${ }^{19}$ Avian diploid
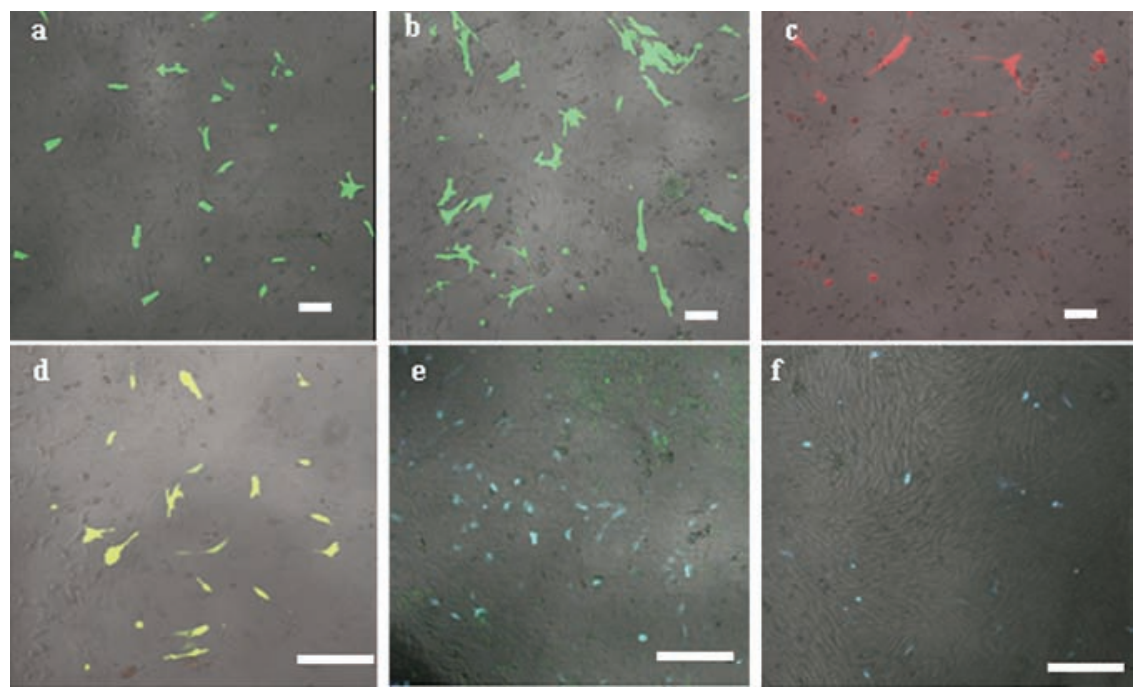

e

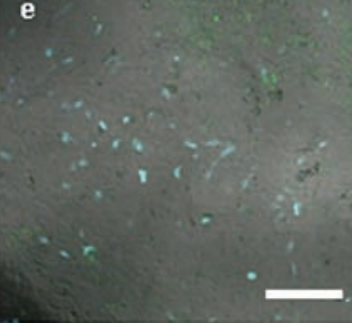

Figure 6. Comparison of six fluorescent proteins at $24 \mathrm{~h}$ after transfection using a confocal microscope with excitation wavelengths of $433 \mathrm{~nm}-588 \mathrm{~nm}$ to determine the transfection efficiencies. (a to $f$ ) were the transfection results of pEGFP-C1, pEGFP-N3, pDsRed1-N1 pEYFP-N1, pECFP-N1and pECFP-mito respectively.

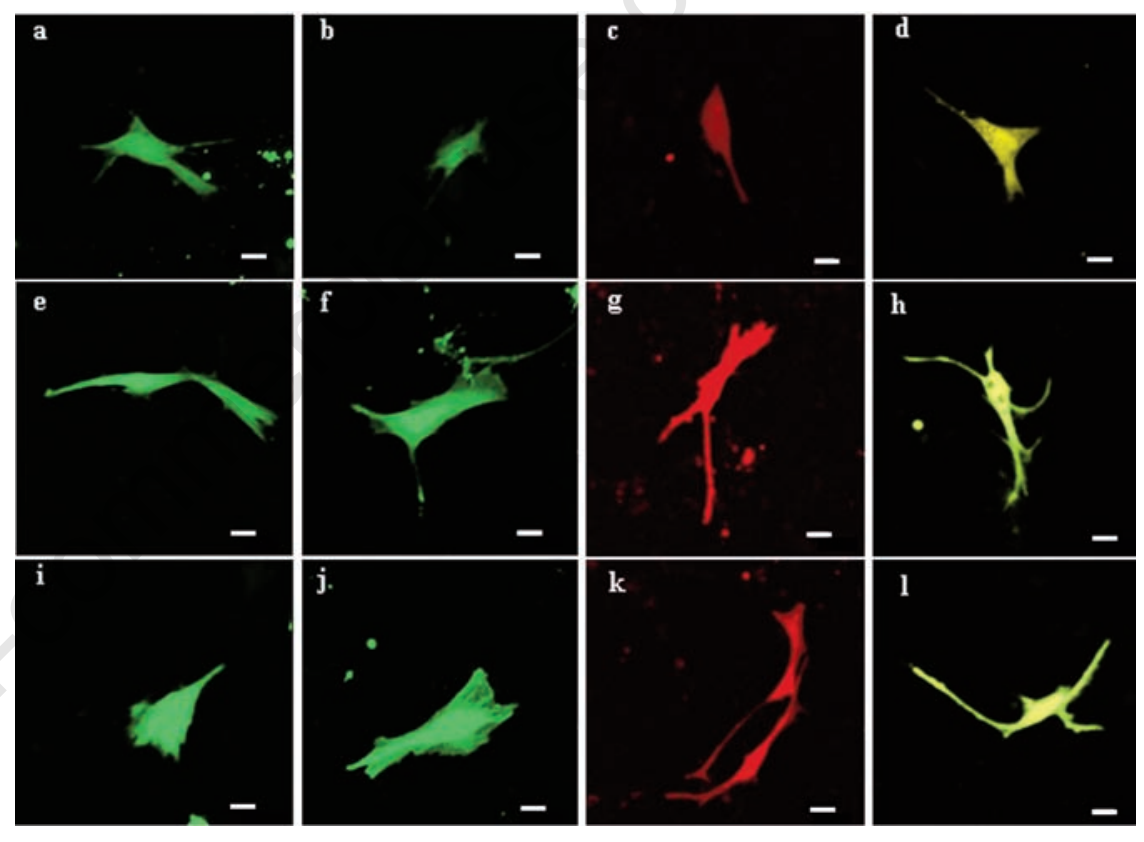

Figure 7. Expression of pEGFP-C1, pEGFP-N3, pDsRed1-N1 and pEYFP-N1 gene in Jingning chicken fibroblasts. (a-d) Fluorescent proteins of pEGFP-C1, pEGFP-N3, pDsRed1-N1and pEYFP-N1 at $24 \mathrm{~h}$ after transfection; (e-h) fluorescent proteins of pEGFPC1, pEGFP-N3, pDsRed1-N1and pEYFP-N1at $48 \mathrm{~h}$ after transfection; (i-l) fluorescent proteins of pEGFP-C1, pEGFP-N3, pDsRed1-N1 and pEYFP-N1at $72 \mathrm{~h}$ after transfection.
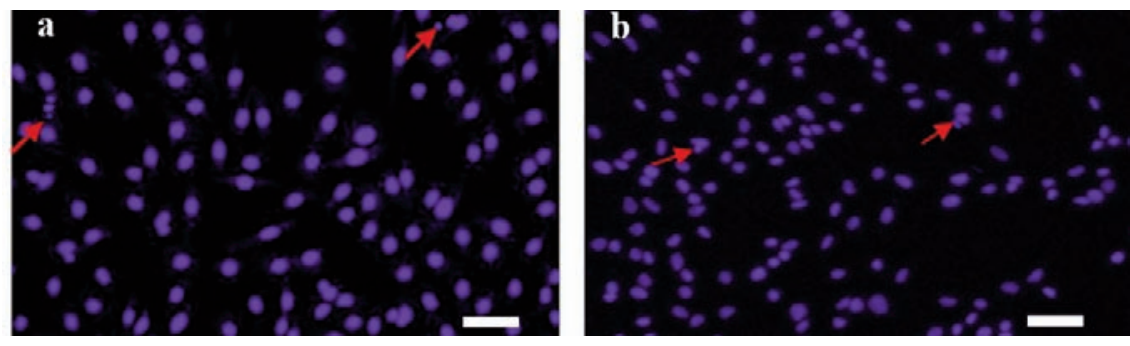

Figure 8. Apoptosis detection of pEGFP-C1 and pEYFP-N1 transfected fibroblasts stained with DAPI. Apoptosis detection of cells (a) upon pEGFP-C1 transfection and (b) upon pEYFP-N1 transfection at $24 \mathrm{~h}$ stained with DAPI. 
chromosome number are greatly diversified, the majority of which ranged from 78 to 82 . Chicken macrochromosome number is $7.8 \pm 0.9$, fluctuating from 6 to 9 , and the microchromosome number is $31.9 \pm 2.5$, the range varying from 24 to 35 . In this study, the results showed that the diploid chromosome number of Jingning chicken was $2 n=78 \pm 0.9$ in 100 cells, with 10 pairs of macrochromosomes and 29 pairs of microchromosomes. The proportion of $2 \mathrm{n}=78$ cells were $97 \%$, as detected in 100 cells. Most Jingning chicken chromosomes are tiny and may be easily lost in the preparation process or hardly identified by the interference of dye; this makes their count and even the morphological observation rather difficult. Therefore, the colchicine and hypotonic treatment should be carefully controlled in the metaphase preparation.

In cell cultures from primary explants, contamination may occur due to the undesired presence of cells from different species or tissues. Isoenzyme polymorphisms exist in different species, different races, different individuals and even different tissues of the same species. Therefore, biochemical analysis of isoenzyme polymorphisms is a standard method for the detection of cell line cross-contamination in the current important biological resource centers throughout the world, such as the ATCC, ECACC (European collection of animal cell cultures) and DSMZ (Deutsche Sammlung von Mikroorganismen und Zellkulturen). ${ }^{20}$ The cell line cross-contamination can be detected when presence of other cells is higher than $10 \%{ }^{21} \mathrm{LDH}$ and $\mathrm{MDH}$ are pivotal enzymes in glycolysis and citric acid cycle, two major metabolic pathways of animals. Genes and metabolites doubly control LDH gene expression, so the expression of LDHs had species and tissue specificity. We optimized the method of ATCC and detected the five bands of LDHs, corresponding to LDH1, LDH2, LDH3, LDH4 and LDH5. Chicken MDHs includes m$\mathrm{MDH}$ and s-MDH, among which s-MDH bands are generally large, highly active and higher in content than m-MDH. In the results, MDHs of Jingning chicken embryonic fibroblast line displayed two bands, s-MDH and mMDH. The motility rate of $s-\mathrm{MDH}$ is higher than that of $\mathrm{m}-\mathrm{MDH}$, similar as in the early development of chicken embryos, indicating that MDH activities of in vitro cultured cells were similar to those of the source organs in the adults. This six enhanced fluorescent proteins in the present study are characterized with stable structure, as well as effective and germ-line independent expression. They are characterized by brighter fluorescence, more efficient expression of the transcription than lacZ, CAT and other common fluorescent markers in animal cells. ${ }^{22}$ High transfection efficiencies were obtained at $24 \mathrm{~h}$. When the transfection efficiencies decreased, bright fluorescence could still be observed even after a week, indicating that the exogenous genes could be replicated, transcribed, translated and subsequently modified in the fibroblasts. The results provided solid theoretical and technical basis for structural genomics, functional genomics and transgenic researches concerning the Jingning chicken in the future. Trypan blue tests suggested that the viabilities after transfection were nonsignificantly different $(\mathrm{P}>0.05)$ from the controls (91.4\%), implying that the transfection conditions used and the expression of fluorescent proteins did not affect cell growth and proliferation.

In summary, a Jingning Chicken cell bank containing biologically normal and genetically stable fibroblasts was successfully established, meeting the standards of cell line quality standards of the major international culture collection and centers. Exogenous gene expression results supported their strong vitality and rationalized their applications in transgenic therapies and genetics. The precious genetic resource of Jingning chicken was therefore well preserved at cell level, and could be used as biological materials for genetics, biomedical sciences, cell and molecular biology, immunology and so forth.

\section{References}

1. Guan WJ. The construction and identification of the cell bank of species of domestic animal on the brink of extinct. Rev China Agric Sci Technol 2002;6:66-7.

$2 \mathrm{Wu} \mathrm{CX}$. The theory and technology of the conservation of animal genetic resources: the specie foundation of animal agricultural continuing development in 21 century. Journal of Yunnan University (Natural Sciences Edition) 1999;21:7-10.

3. Xu GF, Chen KW. Photograph Album of China Indigenous Poultry Breeds. 2003, China Agricultural Press, Beijing, China..

4. Guan WJ, Ma YH, Zhou XY, Liu GL, Liu XD. The establishment of fibroblast cell line and its biological characteristic research in Taihang black goat. Rev China Agric Sci Technol 2005;7:25-33.

5. Zhou XM, Ma YH, Guan WJ, Zhao DM. Establishment and identification of Debao pony ear marginal tissue fibroblast cell line. Asian Austral J Anim 2004;17:1338- 43.

6. Ren FL. In vitro cultivation and freezing of bovine skin fibroblast cells. Scalper Mag 2002;28:8-10.

7. Qi YT, Tu YD, Yang D, Chen Q, Xiao J, Chen YQ, et al. Cyclin A but not cyclin D1 is essential in c-myc-modulated cell cycle progression. J Cell Physiol 2007;210:63-71.

8. Suemori H, Yasuchika K, Hasegawa K, Fujioka T, Tsuneyoshi N, Nakatsuji N.. Efficient establishment of human embryonic stem cell lines and long-term maintenance with stable karyotype by enzymatic bulk pas- sage. Biochem Biophys Res Commun 2006;345:926-32.

9. Weingartl HM, Sabara M, Pasick J, van Moorlehem E, Babiuk L. Continuous porcine cell lines developed from alveolar macrophages partial characterization and virus susceptibility. J Virol Methods 2002; 104:203-16.

10. Doyle A, Hay R, Kirsop BE. Animal cells (Living resources for biotechnology). 1990, Cambridge University Press, Cambridge, UK.

11. Simpson RJ. Proteins and Proteomics. A Laboratory Manual. 2003, Cold Spring Harbor Laboratory Press, Cold Spring Harbor, NY, USA.

12. Hay RI. Cell line preservation and characterization. In: Freshney RI, (ed.) Animal Cell Culture: A Practical Approach. 2nd rev, 1992, 0xford University Press, Oxford..UK, pp. 104-35.

13. Wu HM, Guan WJ, Li H, Ma YH. Establishment and characteristics of white ear lobe chicken embryo fibroblast line and expression of six fluorescent proteins in the cells. Cell Biol Int 2008;32:1478-85.

14. Costa UM, Reischak D, da Silva J, Ravazzolo AP. Establishment and partial characterization of an ovine synovial membrane cell line obtained by transformation with Simian Virus $40 \mathrm{~T}$ antigen. J Virol Methods 2005; 128:72-8.

15. Sun YL, Lin CS, Chou YC. Establishment and characterization of a spontaneously immortalized porcine mammary epithelial cell line. Cell Biol Int 2006;30: 970-6.

16. Li LF, Yue H, Ma JZ, Guan WJ, Ma YH. Establishment and characterization of a fibroblast line from Simmental cattle. Cryobiology 2009;59:63-8.

17. MacLeod RA, Dirks WG, Matsuo Y, Kaufmann M, Milch H, Drexler HG. Widespread intraspecies cross-contamination of human tumor cell lines arising at source. Int J Cancer 1999;83:555-63.

18. Xue QS. The principle and technique of in vitro culture. 2001, Science Press, Beijing, China, pp 432-44.

19. Ladjali-Mohammedi K, Bitgood JJ, TixierBoichard M, Ponce de Leon FA. International System for Standardized Avian Karyotypes (ISSAK): standardized banded karyotypes of the domestic fowl (Gallus domesticus). Cytogenet Cell Genet 1999;86:271-6.

20. Drexler HG, Dirks WG, MacLeod RAF. False human hematopoietic cell lines: cross-contaminations and misinterpretations. Leukemia 1999;13:601-7.

21. Nims RW, Shoemaker AP, Bauernschub MA, Rec LJ, Harbell JW. Sensitivity of isoenzyme analysis for the detection of interspecies cell line cross-contamination. In Vitro Cell Dev Biol Anim 1998;34: 35-9.

22. Heim R, Cubitt AB, Tsien RY. Improved green fluorescence. Nature 1995;373:663-4. 